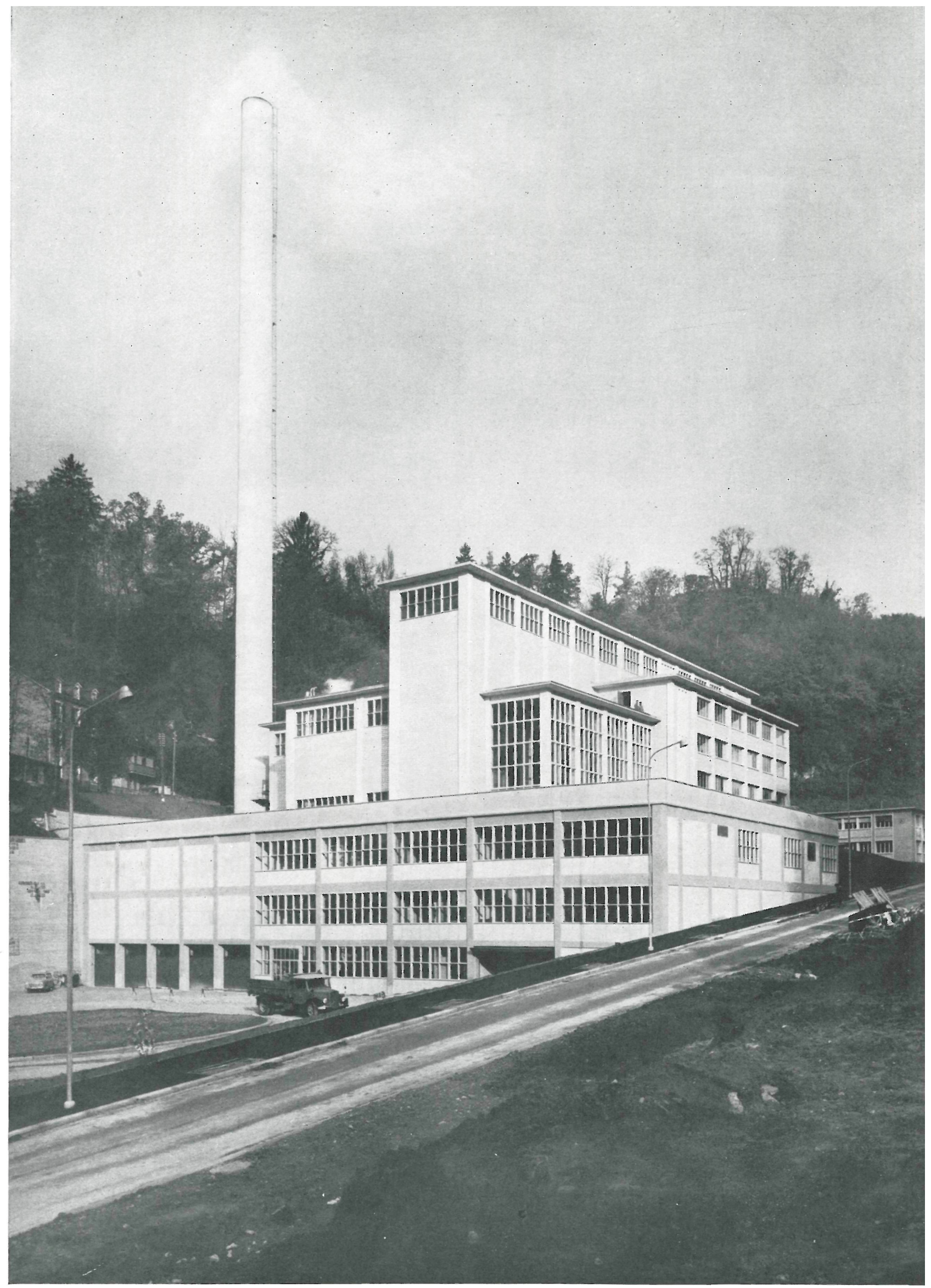

\title{
estación incineradora
}


En esta obra que presentamos,

el carácter arquitectónico y constructivo de la misma ha quedado empañado por su carácter significativo.

En una palabra,

el proyecto-el juego de volúmenes, los materiales empleados, su composición estética...-

ha pasado a un segundo plano ante la esencia del mismo.

El problema de la destrucción de las basuras

es uno de los más agudos con que se encuentran los municipios de todas las ciudades del mundo.

Suiza, con su fábrica incineradora de Lausana,

parece que ha marcado la pauta para que desaparezcan

esos inevitables vertederos que circundan los alrededores de todas

las ciudades y que sólo

constituyen un foco de peligro para la salud pública.

Esta factoría incineradora está considerada

como modelo en Europa.

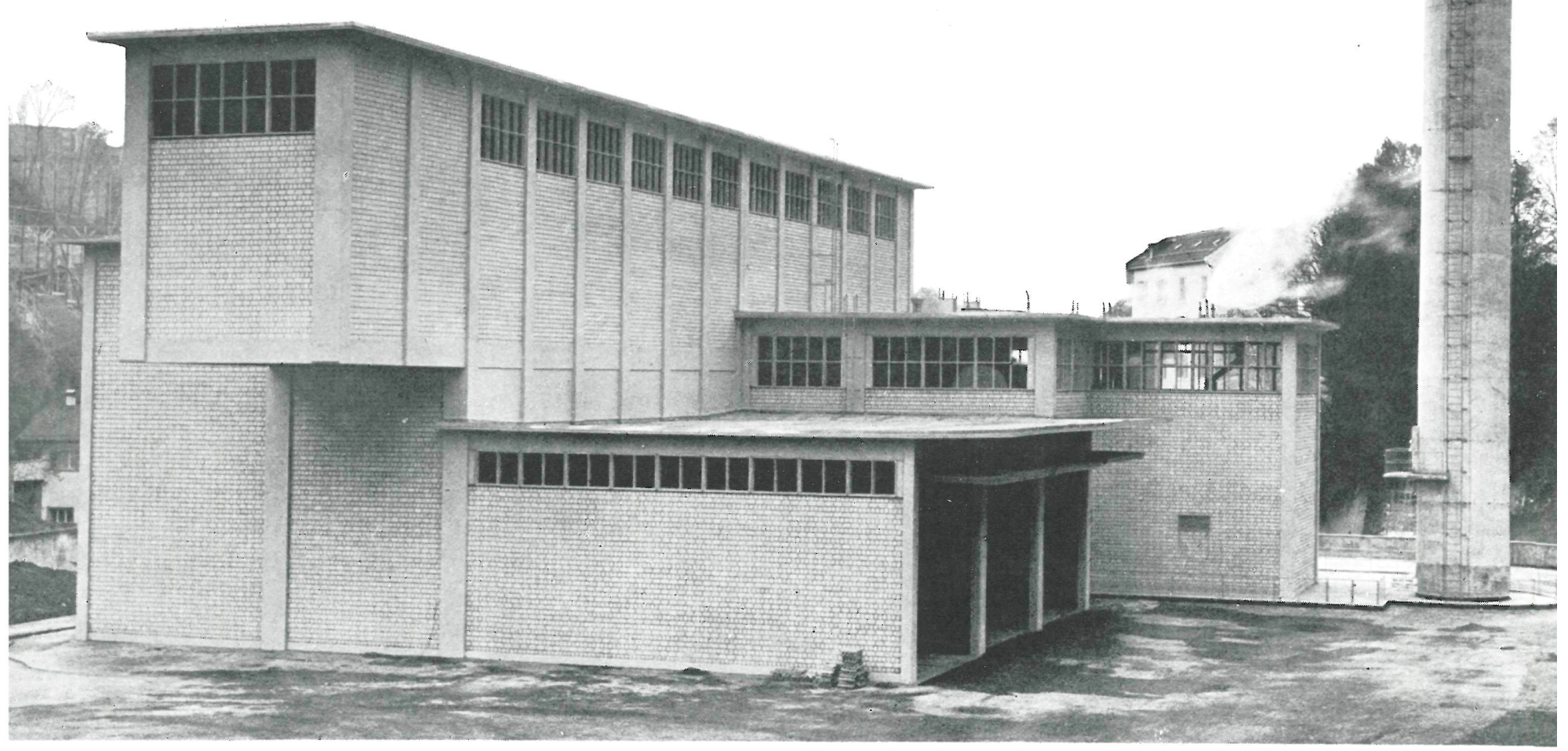




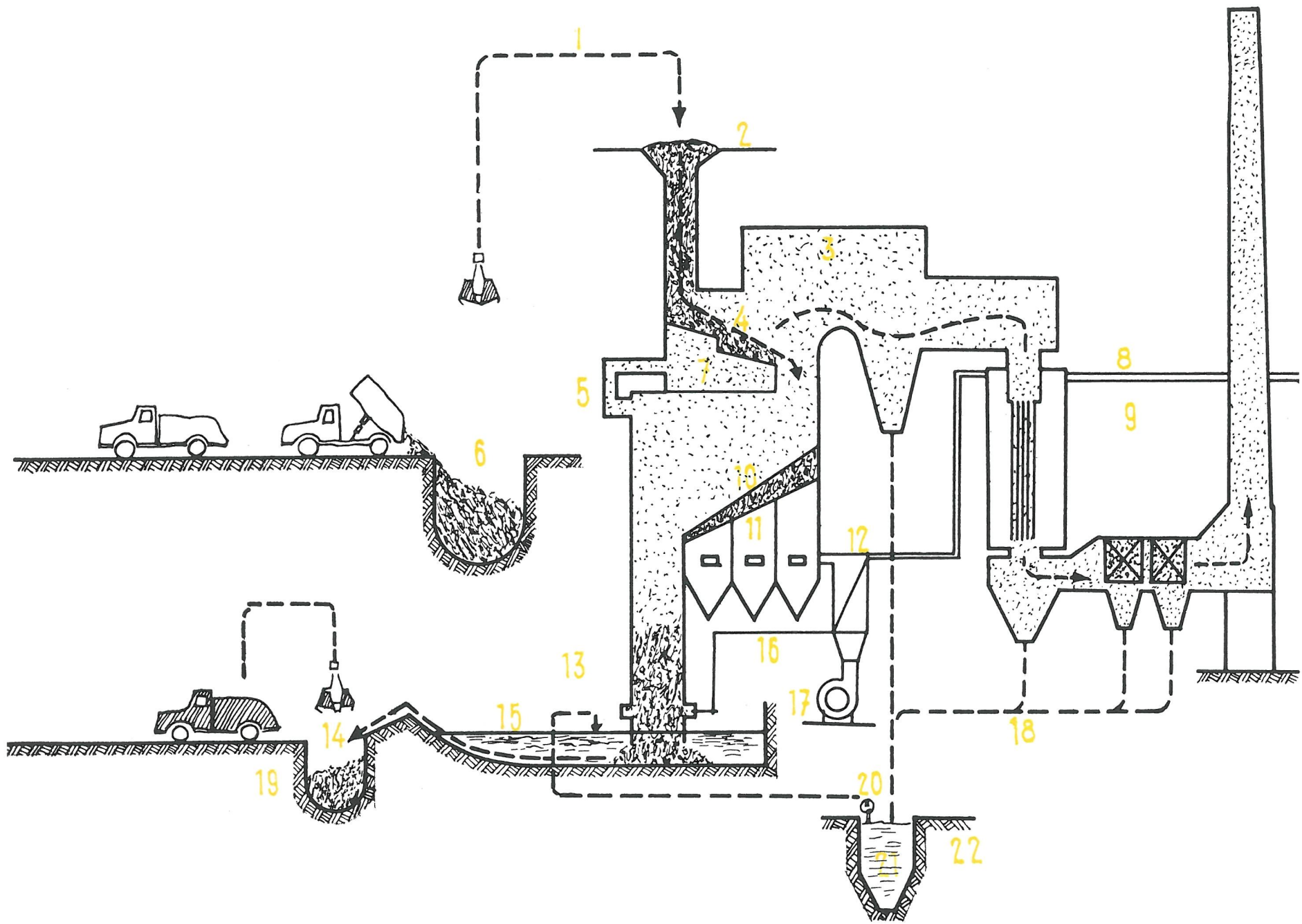

1. Basuras domésticas.-2. Horno.-3. Cámara de combustión, oxidación y esterilización de humos.-4. Presecado y encendido.-5. Aire comprimido.-6. Fosa de basuras.-7. Parrillas del presecado.-8. Calderas.-9. Filtro electrostático.-10. Combustión.-11. Parrilla principal.-12. Precalentamiento del aire.-13. Calcinación de residuos de la combustión y estilización del calor latente de las carbonillas.-14. Fosa-depósito de carbonillas.-15. Salida de carbonillas.-16. Aire.-17. Ventilador soplante.-18. Cenizas volátiles +agua =lodos.-19. Carbonillas estériles e inodoras. -20. Bomba.-21. Barros.22. Sumidero de bombeo.

Sus instalaciones, dotadas con los últimos adelantos de la técnica, no sólo acaba con los desperdicios reduciéndolos a cenizas, sino que el calor producido en la combustión es transformado en vapor de agua, y éste es aprovechado para convertirlo en energía eléctrica y dar calefacción central a una serie de edificios próximos. Las cenizas también tienen su aprovechamiento, bien como abonos agrícolas, bien como antideslizante para las carreteras heladas. Un sistema de filtros electromagnéticos hace que Ios residuos vaporosos que afloran al espacio lleguen ligeros e inofensivos a través de la boca de la chimenea.

Es, por ello, por lo que este quemadero de basuras se alza orgulloso dentro del recinto urbano, demostrando que su presencia es tan necesaria para la ciudad como puede serlo cualquier otro edificio público. Su chimenea, de $80 \mathrm{~m}$ de altura, pregona el avance que la técnica pone al servicio del hombre.

Las principales características técnicas de esta instalación son:

2 hornos de Roll núm. 100, con capacidad de incineración de 100 t de basura en veinticuatro horas a marcha normal. 
Cada horno tiene una altura de $17 \mathrm{~m}$; estructura metálica revestida con ladrillo refractario de 40 a $75 \mathrm{~cm}$ de espesor, y dos parrillas: una de secado interior $\mathrm{y}$ otra de combustión.

2 calderas, con superficie de calentamiento de $550 \mathrm{~m}^{2}$ y superficie de sobrecalentamiento de $65 \mathrm{~m}^{2}$.

Tiene una capacidad de $10 \mathrm{t}$ de vapor por hora a una temperatura de $250^{\circ} \mathrm{C}$ y una presión de 20 kilos por centímetro cuadrado.

Instalación de despolvorización, formada por un filtro bicameral electrostático, trabajando bajo una tensión de 30 a 50.000 voltios.

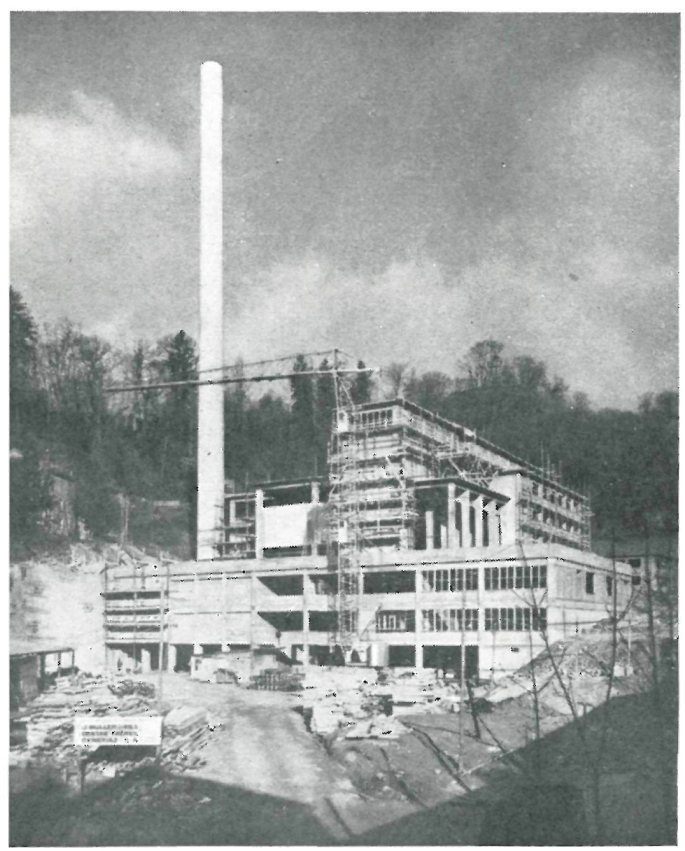

construccion
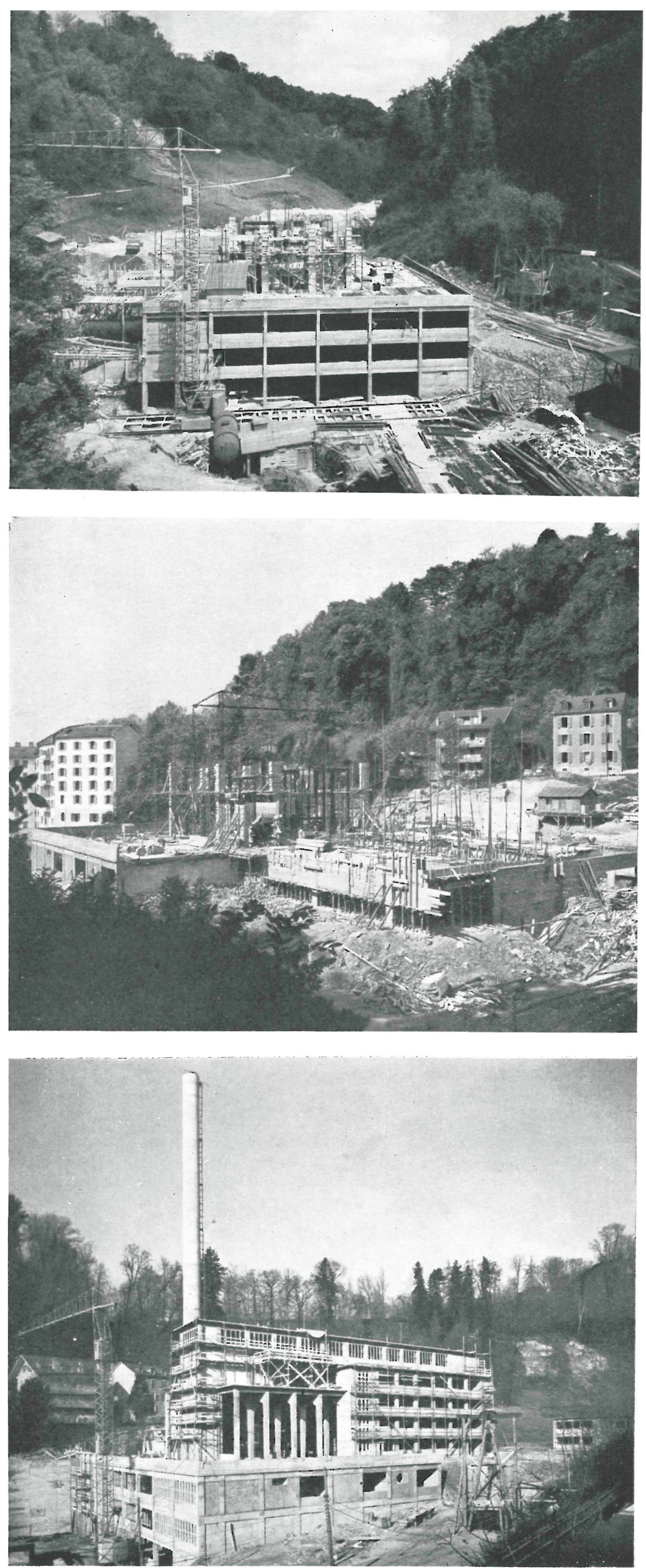
Chimenea, con estructura de hormigón armado revestida interiormente con ladrillo refractario. Su altura es de $80 \mathrm{~m}$, y los diámetros en los puntos más bajo y más alto son, respectivamente, de 3,50 y 2.50 metros.

Pueden calcularse en $27.000 \mathrm{t}$ al año las que se pueden incinerar, y bastan sólo 17 personas para manejar tan compleja instalación. Un quemador especial en los hornos permite utilizar el alto valor la energía eléctrica cuando la demanda lo requiere. La venta de la energía producida por la incineración de todos los desperdicios cubre los gastos de explotación de la fábrica. calorífico de los aceites desechados para aumentar

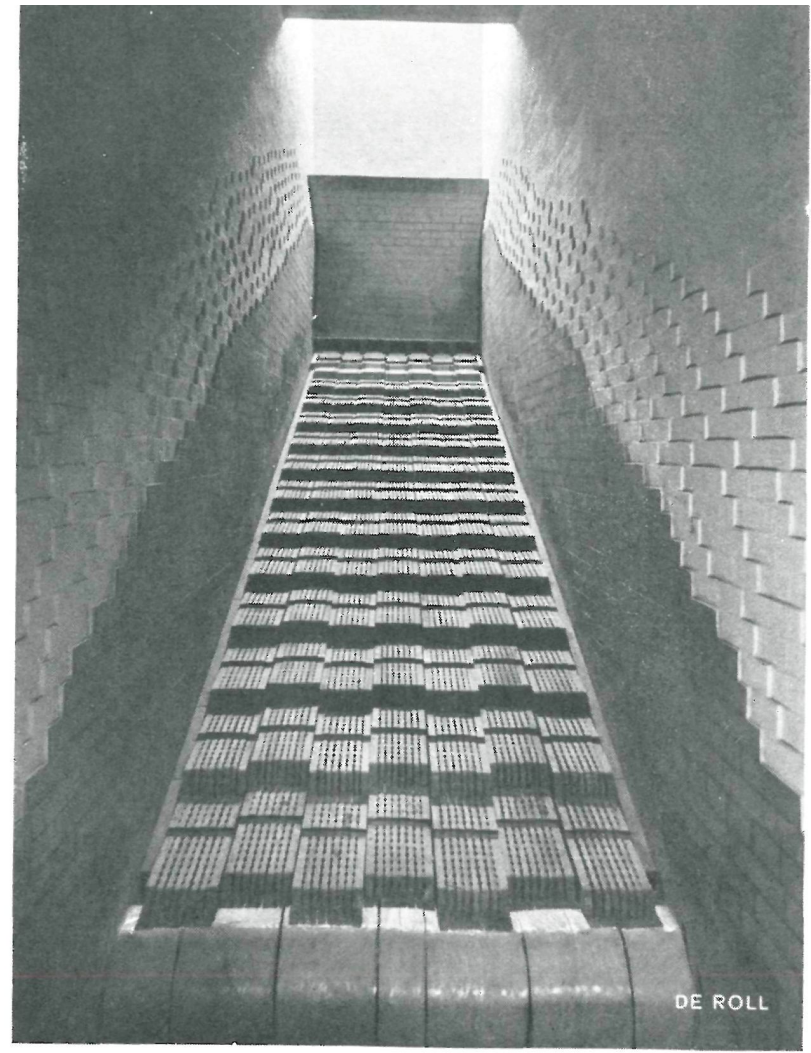

Fotos: LAUSANN

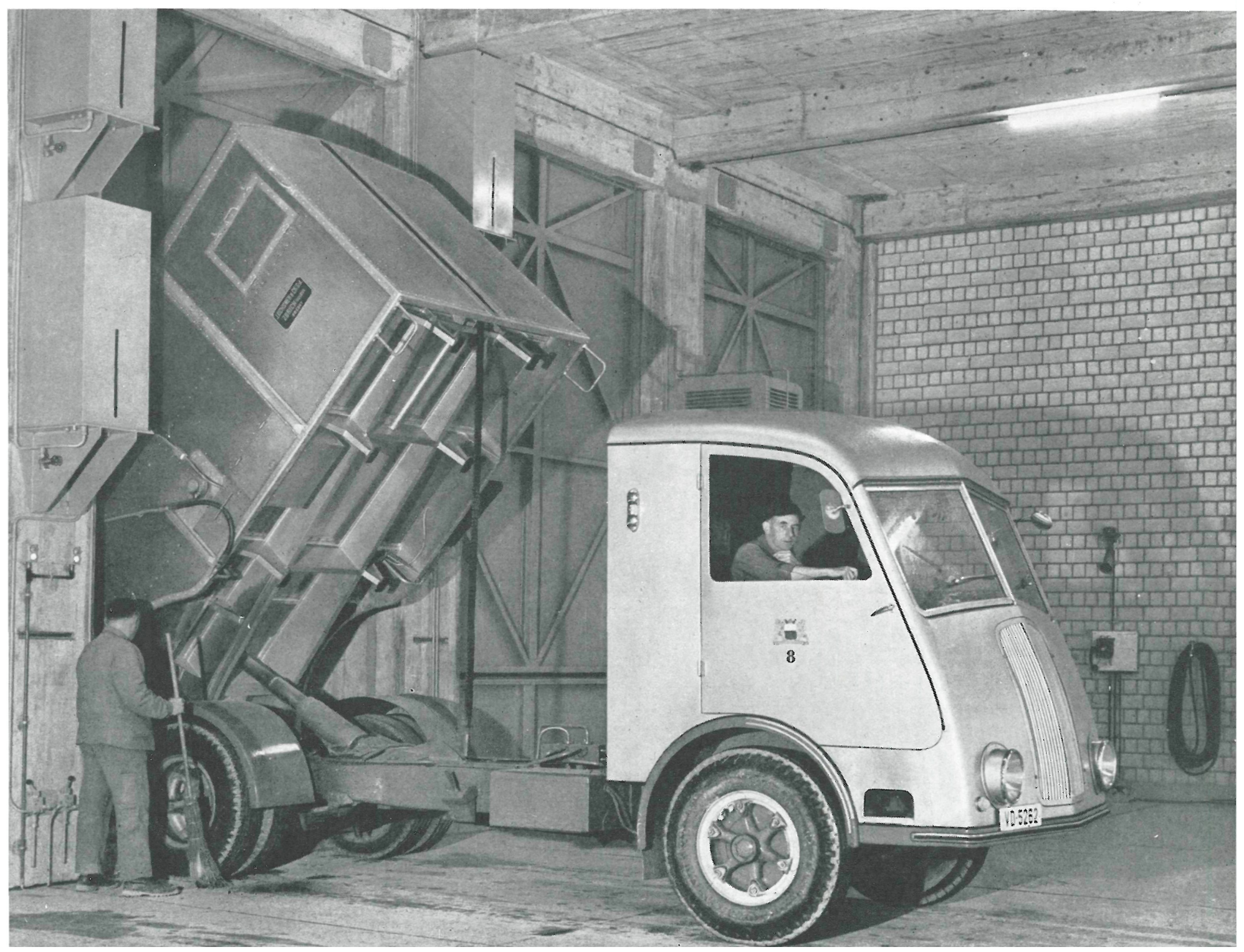

